\title{
TUBERCULOUS GLANDS OF THE NECK
}

\author{
By Ronald Reid, M.S.(Lond.), F.R.C.S.(Eng.)
}

Tuberculosis in the lymphatic glands of the neck is, in this country, a common disease. Though its incidence has declined with the growth of the Public Health Services, it is important because in most instances it is the reaction of the child to his first contact with tubercle bacilli.

The first accurate description of the disease is by Richard Wiseman, Surgeon to King Charles II, in his book 'Severall Chirurgicall Treatises,' published in 1676 . It was known as struma or scrofula or king's evil, for it was cured by the ' royal touch,' a divine power of kings dating back to the $5^{\text {th }}$ century A.D., and much practiced by the Stuarts, Queen Anne being the last royal healer. With the introduction of antiseptics and anaesthesia, the treatment of tuberculous glands passed from the theory of medicine to the practice of surgery, and during the first decade of the present century as much as a third of the surgeons' operations were upon glands of the neck. The pendulum had swung the full arc, vast block dissections were practiced leaving scars of monumental ugliness. Under rational control and treatment, tuberculosis will no doubt decline in this country as it has where children are protected against the sources of infection, particularly tuberculous cattle.

\section{Surgical Anatomy}

A tuberculous gland in the neck is the outward sign that tubercle bacilli have successfully invaded the lymphatic tissues related to the upper parts of the respiratory and alimentary tracts. The nose and naso-pharynx, which conduct, condition and filter the air, and the pharynx, the common air and food passage are lined by a vascular mucous membrane containing a rich network of lymphatic tissues and channels. The tissue exists also in certain aggregations, notably the pharyngeal and palatine tonsils. From the mucosa and lymphoid masses vessels drain into the deep cervical glands disposed in chains along the great vessels of the neck, chains which receive the lymph from all the superficial glands of the head and neck and are continuous below with the glands in the mediastinum, including the tracheobronchial groups draining the lungs.

The deep cervical chain is divided into superior and inferior parts. The superior is divided into two groups, medial and lateral to the internal jugular vein. The medial group is in contact with the pharyngeal wall and extends behind the pharynx to link with glands in the opposite side of the neck. One gland, at the lower border of the posterior belly of the digastric muscle is known as the tonsillar gland from the frequency with which it swells in tonsillitis. The lateral group of deep cervical glands surrounds the spinal accessory nerve and extends out into the posterior triangle of the neck. The lymph from all these passes down by the lower deep cervical glands to enter the venous system at the base of the neck.

For convenience of description lymphatic glands are divided into chains and groups but they are one continuous system through which infection may spread in any direction.

\section{Aetiology and Pathology}

As Osler stated, the tubercle bacillus is ubiquitous and capable of long survival outside the living body. It causes immeasurable misery and takes a heavier toll of human lives than any other disease. The sources of external infection are phthisical patients and tuberculous cows, from sputum and infected milk, sources which unfortunately are often untraceable. Once tuberculosis has gained a foothold, internal infection or spread within the body proceeds by direct invasion, by blood stream dissemination or by transmission along the lymphatic channels, if and when the natural resistance of the patient cannot hold the enemy at bay.

Practically all human beings at some stage of their lives, usually in childhood or adolescence, fall victims to tuberculosis and in the fixation of and resistance to this first contact, the primary infection, the lymphatic and endothelial systems play the important part. Infection in infancy, before the lymphatic arrangements are fully developed, is often overwhelming, whilst in old age, during the years of decline, tuberculosis again often pursues a peculiarly rapid and destructive course.

The two common forms of the bacillus, human and bovine, both cause tuberculous glands in the neck. Blacklock (1947) has shown that the human 
bacillus is the common variety in town dwellers, who live in crowded dwellings but consume heattreated milk, whereas in the country where there is less congestion of population and milk is drunk raw, the bovine bacillus is the rule. His findings emphasize the need for the control of infection by public health policy.

The tubercle bacillus possesses a remarkable power of penetrating mucous membranes without causing an immediate and discernible local reaction. When once established in living tissue there is an exudative and cellular response and, unless the invaders are destroyed out of hand, they pass by lymphatic channels to the glands which drain the affected area. How long this passage takes is unknown but by the time living bacilli have settled in the glands a general body sensitivity has developed. It is now generally accepted that tubercle bacilli produce neither exotoxin nor endotoxin and that the cellular and exudative response to their presence, which varies in intensity from a mild reaction to massive tissue death, is essentially an allergic phenomenon. This reaction is seen in purest form in the primary infection. Secondary lesions, arising by further external infection or by internal seeding from a pre-existing focus, occur in already sensitized tissue and their development is different from that of the primary infection and is outside the scope and purpose of this paper.

The primary complex consists of the point of entry of the tubercle bacilli, the draining lymphatic glands and the intervening channels. The reaction in the gland overshadows in its intensity that at the point of entry which may be anywhere on the surface of the body, but is practically always in the respiratory or alimentary tracts. If the point of entry is in the upper air or food passages, the reacting glands are in the neck; if the lung be affected, the tracheo-bronchial glands are involved and may so swell as to obstruct a main bronchus; if the alimentary tract be the site of penetration, the mesenteric glands enlarge, in some instances with such violence as to cause ascites and symptoms of an acute abdominal crisis. There is little doubt that in most cases tuberculous glands in the neck are the glandular component of a primary complex and being conveniently situated for observation their progress can be followed. Bacilli having gained a foothold, an allergic response develops and the glands enlarge rapidly; oedematous periadenitis binds them to all surrounding structures. This violent reaction causes general malaise and pyrexia which usually does not reach the high levels. of pyogenic infection with which tuberculosis may easily be confused at first. In the gland itself, tubercles are formed and tissue death occurs to an extent which depends upon the two opposing factors of virulence $\sum_{1}$ dose of the bacilli, and the natural resistance of the patient. As natural resistance rises the violent reaction subsides, periadenitis recedes and the glands once matted together become discrete; those which have escaped destruction returnoto normal. Where there has been necrosis the caseōis pus forms a cold abscess which either discharges to the body surface or is in time encapsuled, $\frac{\mathrm{dn}}{\mathrm{m}}$ spissated and calcified. Those bacilli which suirvive are buried alive in calcium to remain a possible danger in days to come.

It should not be concluded that all tuberculs neck glands are part of a primary complex in the neck. Tuberculosis may spread to the base of the neck from infected glands in the thorax, whichin turn arise from lesions in the lungs or in otker intrathoracic structures. Also there is a formoof diffuse enlargement of glands arising simpltaneously over wide fields on one or both sidesoff the neck. This form is more commonly seenoin adults and there is little general or local reaction of an exudative character. Rather are the glands fibro-caseous, firm and discrete from the firft; there is no reaction as in the primary complex ofid it is tempting to suggest that they are secondary lesions due to the late spread along lymphat

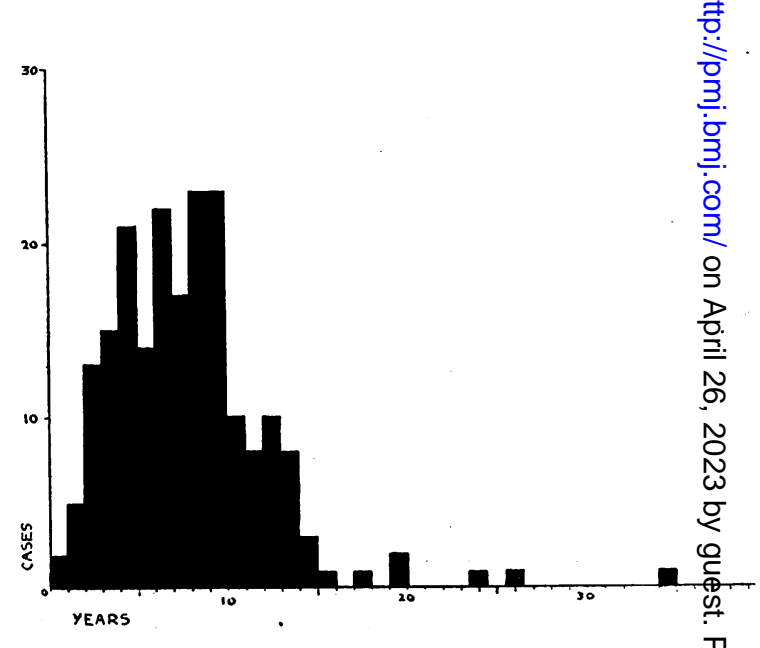
even to blood stream infection.

\section{Clinical Picture} Tuberculous glands in the neck is a diseaseopof childhood but adults and the aged are not immug̃e, and both sexes are equally affected. Tables $\mathbf{I}$ and 2 show the incidence in a personal series $\overrightarrow{0}$ of 200 cases.

FIG. I.-Incidence in age groups.

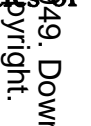

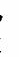


TABLE 2

SEX INCIDENCE

Males

Females

\begin{tabular}{llllllr}
$\ldots$ &.. & $\ldots$ & $\ldots$ & $\ldots$ & $\ldots$ & 107 \\
. &. &. & $\ldots$ &. & $\ldots$ & 93 \\
Total &. & $\ldots$ & $\ldots$ &.. & $\ldots$ & 200 \\
\hline
\end{tabular}

The disease occurs in three clinical forms:-

(a) Local caseous tuberculous lymphadenitis of the upper cervical chain.

(b) Local caseous tuberculosis of the lower cervical chain.

(c) Diffuse tuberculous lymphadenitis.

TABLE 3

Site of Disease

$\begin{array}{llllll}\text { Upper Deep Cervical } & \ldots & \ldots & \ldots & \ldots & 196\end{array}$

$\begin{array}{llllll}\text { Posterior Triangle } & \ldots & \ldots & \ldots & \ldots & 23\end{array}$

$\begin{array}{llllllr}\text { Supraclavicular } & \ldots & \ldots & \ldots & \ldots & \ldots & 4\end{array}$

$\begin{array}{lllllll}\text { Total } & . & \ldots & \ldots & \ldots & \ldots & 200\end{array}$

Table 3 shows that the first form is the most common. It is this form which is the primary complex of childhood, the site of invasion being in the nearby air and food passages. Perhaps catarrhal infection provides a state of lessened resistance in childhood through which infection can gain an entry.

(a) Caseous tuberculous lymphadenitis of the upper chain is of sudden or gradual onset, maybe following an acute specific fever. If acute it is impossible to distinguish tuberculous from streptococcal lymphadenitis, and only the clinical course of the disease or the response to chemotherapy may settle the etiology.

At first the upper cervical glands are swollen, tense and matted together to form a diffuse rubbery swelling behind the angle of the jaw. The tonsils are often enlarged and there may be some swelling of glands on the other side of the neck. If infection is heavy and resistance poor the affected glands break down and form an abscess which escapes from the gland capsule, penetrates the deep fascia and appears on the surface of the neck, usually at the lower border of the gland mass about half way down the sternomastoid muscle. This ' collar-stud' abscess with its deep and superficial loculi connected by a narrow neck is characteristic of tuberculosis. The overlying skin soon becomes oedematous and reddened and gives way allowing the pus to discharge. The process is accelerated by secondary septic infection and at its worst may involve the destruction of much skin, subcutaneous tissue and superficial muscle. As the natural response of the patient combats the infection, periadenitis recedes and the glands become discrete and palpable. The lightly touched return to normal, leaving the seriously damaged glands as firm nodes behind the angle of the jaw with maybe other glands enlarged in the posterior triangle or down the deep. cervical chain. In time the tuberculous infections is overcome, calcium is deposited and the glandso can be felt as stony nodes in an otherwise normato neck, with perhaps a sinus or a puckered scar too mark the battlefield.

Thus caseous tuberculous lymphadenitis of thei upper chain passes through three stages in the continuous process of natural repair.

Stage I. This is the acute phase of invasion when the glands are matted together by perio adenitis.

Stage 2. Periadenitis has receded leaving the glands more discrete, firm and movable.

Stage 3. All periadenitis has disappeared and of few hard stony nodules with or without a sinus్ remain.

(b) Caseous tuberculous lymphadenitis of the lower cervical chain occurs commonly in adolescene or later life. The glands are either a solitary in $=$ fected group or they are the upper nodes of $\mathbb{O}$ chain of tuberculous mediastinal glands and they form a tumour in the supraclavicular region deep under the lower end of the sterno-mastoid muscle In the acute phase there may be considerable poing and constitutional disturbance and much pe $\mathrm{i}$. adenitis, but in the chronic stage a cold abscess sinus are common.

(c) Diffuse tuberculous lymphadenitis is a diseas distinct from, and far less common than, the otheg forms and occurs at any age. In the young botlo sides of the neck may be filled with huge sof glands. Later the glands are rubbery and re응 semble lymphadenoma or one of the reticuloses The glands generally remain discrete and movable although occasionally several may be matted. together to form a rubbery tumour. Generat symptoms are not marked, the progress of the disease is slow and the results of surgical excisiow. are disappointing. In later life slow breakdowi and caseation may occur in many glands on one or both sides of the neck, forming sinuses or scas tissue without the preceding enlargement and in? flammation which distinguishes the primary ins fection of childhood.

\section{Differential Diagnosis}

The first step in the differential diagnosis is the recognition of whether the swelling is of lymphatic glands or otherwise, and the second step is the identification of their tuberculous etiology.

Swellings other than in lymphatic glands are usually easily recognizable and the following con: ditions must be considered:-

(a) A branchial cyst is a rounded fluctuant 
flabby swelling in the upper part of the neck near the angle of the jaw, of slow progress; detached from the skin and translucent to light. Unless infected, signs of inflammation are absent and occasionally the cyst may communicate with a branchial fistula which traverses the two heads of the sternomastoid muscle to surface above the sternoclavicular joint.

(b) Parotid and submaxillary swellings are usually inflammatory or associated with calculus. They occur in adult life and tend to become painful at meal times when the gland is active. $\mathrm{X}$-rays may show a stone.

(c) Swellings of the thyroid gland are unlikely to cause confusion for they are situated low down in the neck near the mid-line and move on swallowing with the trachea. A thyroglossal cyst situated near the hyoid bone may resemble an infected gland of the sub-mental group.

(d) Cystic hygroma is an uncommon tumour occurring in the posterior triangle of the neck in children. It is soft and translucent without the slightest trace of inflammation.

(e) Actinomycosis bovis is a brawny inflammatory swelling with multiple sinuses which discharge sulphur granules of the ray fungus. It arises anywhere in the neck, is not confined to any one tissue and does not cause discrete glandular enlargement.

Swellings of lymphatic glands. I. Inflammatory. (a) Acute septic lymphadenitis is recognized by the rapid onset with a high temperature, malaise and a hot brawny swelling of the glands together with the presence of an infected lesion in the drainage area including the throat and the scalp. Time alone may distinguish this condition from tuberculosis in its early stage.

(b) Chronic septic lymphadenitis may be associated with throat infections or with dermatitis and pediculosis of the scalp.

2. Neoplastic disease (a) Secondary carcinoma and branchiogenic carcinoma in lymph glands give rise to hard swellings at an age when glandular tuberculosis is uncommon. Search should be made by special and general examinations for the primary lesion in the mouth, pharynx, thyroid and chest.

(b) The reticuloses are new growths arising anywhere in the reticulo-endothelial system, and give rise to a discrete rubbery swelling of one group of lymphatic glands. Biopsy alone settles the doubt.

3. General disease associated with chronic enlargement of lymphatic glands. (a) Hodgkin's disease causes enlargement of one group of lymphatic glands followed by splenomegaly, the PelEpstein temperature and eosinophilia.

(b) Glandular fever occurs in childhood and is a febrile disease associated with enlargement of the neck glands. The Paul Bunnell test and characteristic changes in the blood count are of diagnostic importance.

The recognition of the etiological factor in lymphadenitis presents no difficulty if there is a sinus, for tubercle bacilli can usually be identified in the discharge. The following special diagnostic tests may be of assistance in cases of doubt:-

I. The Mantoux and Von Pirquet cutaneous sensitivity tests become positive soon after infection with tuberculosis, but in the community a positive reaction is the rule. A negative response to these tests is almost conclusive evidence that the glands are not tuberculous.

2. Aspiration of a cold abscess and examination of the pus directly, by culture or by guinea pig test may occasionally be necessary.

3. Biopsy of glands should be avoided if possible and is rarely necessary except in the diffuse noncaseous forms of tuberculous lymphadenitis, when it is amply justified.

4. A thorough general clinical survey and $X$-ray examination of the chest should never be omitted.

\section{Treatment}

The treatment of tuberculous glands of the neck is based upon the principles which time an $\$$ experience have firmly established as fundamentas for all forms of tuberculosis. The patient must be regarded as a whole; the narrow gaze directed upon the swelling in the neck must be broadened to include the individual who is suffering from a constitutional disease. All that medicine and surgery can do is to assist the patient to overcome the infection; the surgical removal of tuberculous glands is but a step in the general plan of treatment and the moment must be carefully chosen.

It is useful to recall once more the natural progress of tuberculous lymphadenitis. There is the first or active phase when the glands are matted together, the second as resolution proceeds and the third when resistance has overcome the infection leaving encapsulated calcareous debris, the embers of the fire which once raged so fiercely. The aim of treatment is to assist these natural processes of resolution and at a suitable moment to eradicate the diseased tissue. If seen in the early phase the patient should be put at rest in bed, if possible in a sanatorium or hospital equipped for open air treatment. Failing this, home conditions should be made to approach as near as possible to the ideal. Rest in the open air with a liberal diet, including extra fats and vitamins, should be continued until the patient's resistance has been raised and the periadenitis has receded. To assist resolution calciferol in doses of up to 50,000 units daily is of value, but it is doubtful whether a splint 
or plaster collar is helpful, unless it includes the upper part of the chest and head.

The response to constitutional treatment is usually evident in a few weeks, the general health improves, the blood sedimentation rate falls, periadenitis subsides and many enlarged glands resolve. The progress may be assisted by the removal of tonsils and adenoids, by the evacuation of a cold abscess or the treatment of secondary infection.

If the case is seen at a later stage when the glands are already discrete and clear of periadenitis a shorter period of constitutional and other preparatory treatment may suffice to fit the patient for operation. The treatment of glands in the root of the neck, while subject to the principles set out above, depends upon their origin. If associated with disease in the mediastinum or the lung their management becomes part of the treatment of the more serious lesion. If they are strictly local they may be excised at the chosen moment.

In the diffuse and widespread variety of tuberculous lymphadenitis response to all forms of treatment is slow; even the most widespread excisions are often followed by recurrence. In these cases, therefore, treatment must be prolonged and thorough. In some recalcitrant cases radium or radiotherapy may assist resolution or fibrosis of the affected glands.

\section{Operative Treatment}

\section{(a) Abscess}

Tuberculous pus, when once it has burst out of the gland, will inevitably find its way to the body surface, usually the skin a little below the affected neck gland, occasionally in the pharynx. Impending rupture is recognized by redness and oedema. Aspiration is unsatisfactory for the pus is thick and cannot be completely evacuated; therefore a cold abscess should be incised and curetted as soon as the probable point of rupture is recognized. The operation should be done under full aseptic precautions and the wound sutured ; resolution of the glands is accelerated by this procedure.

\section{(b) Secondary infection}

This complication requires appropriate chemotherapy (usually penicillin, for the streptococcus is the common organism), and free incision and drainage.

\section{(c) Excision of glands}

Surgical removal of all the diseased glands is indicated when time and general constitutional treatment have raised the patient's natural re- sistance to the highest level possible, when periadenitis has gone and the glands are discrete. Operations in the early active phase are difficult and dangerous for important structures are matted together and may be damaged, pus may be encountered and wounds only too often break down when the stitches are removed.

I. Anaesthesia should be gas, oxygen and ether through an endotracheal tube to allow of perfect control of airway and an unemcumbered operation field. Careful avoidance of respiratory obstruction during induction is important to minimize vascular congestion. The patient is placed upon his back with the head turned to the sound side, and sandbags placed so as to steady the neck and to throw into prominence the site of operation.

2. Incisions in the neck heal best and leave fine linear scars if placed in the natural transverse lines of the skin. Longitudinal and T-shaped cuts are quite unnecessary and unjustifiable; these scars are most unsightly. Incisions should be placed over the affected glands, which are not necessarily deep to a cold abscess or sinus. The upper deep cervical glands should be approached through an incision just below the angle of the jaw. The surgeon should not hesitate to make two or more transverse incisions if there are many glands or groups, or if invaded or ugly skin requires removal.

The skin incisions should traverse the platysma muscle which is included in the flaps to be raised upwards and downwards. Gauze packs soaked in $I$ in 200,000 adrenalin are used to control oozing, and all bleeding points should be tied off as soon as the flaps have been reflected. A mastoid selfretaining retractor is adjusted to spread the wound and the capsule over the gland mass incised until a layer as near as possible to the gland is reached. The recognition of the correct line of cleavage is important for if it be adhered to damage to the great vessels is unlikely. The gland mass is cleared on one side, the wound there packed with adrenalin gauze and the mass cleared elsewhere. This change of approach and packing reduces haemorrhage to a trivial ooze and vessels and nerves can be identified with ease. All firm and caseous glands should be excised, those soft and gelatinous may be left behind for they will certainly resolve. It is not always easy to be sure when all affected glands have been removed and the wound should be carefully palpated, especially in its deeper parts, firm tissue being picked up for examination.

All affected glands having been cleared, any sinus should be curetted and the wound closed with drainage after careful suture of the muscle and skin.

\section{Results of Treatment}

Before determining a course of action, the 
surgeon should have his aims clearly before him. He must take into account the cost in time, suffering and money and review dispassionately the results so far as they are known of the treatment proposed.

The aim in treating tuberculous glands is to cure the local disease as simply and quickly as is convenient with achieving freedom from recurrence and safety from future outbreaks of tuberculosis elsewhere in the body.

It has been my good fortune to work at Black Notley where all forms of tuberculosis are treated, and there is special provision for children with primary lesions, including neck glands. To my colleague, Dr. M. C. Wilkinson, the medical superintendent, I owe a great debt for teaching the importance of principles and for his co-operation. Recently 302 cases have been followed up with the kind assistance of the tuberculosis officers of the Essex County Council, and the results are tabled below.

TABLE 4

Follow UP OF 302 Cases

Examined Medically Letter Report

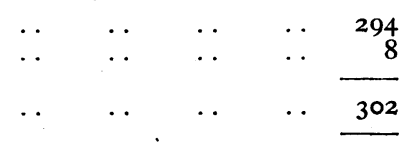

TABLE 5

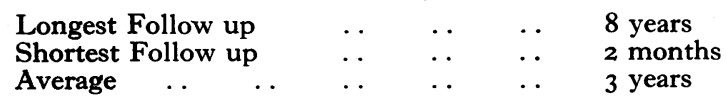

TABLE 6

General State of Health at Follow Up

$\begin{array}{lllllllr}\text { Good } & \ldots & \ldots & \ldots & \ldots & \ldots & \ldots & 298 \\ \text { Bad } & \ldots & \ldots & \ldots & \ldots & \ldots & \ldots & 2 \\ \text { Indifferent } & & \ldots & \ldots & \ldots & \ldots & \ldots & 2 \\ & & & & & & & \\ & \text { Total } & \ldots & \ldots & \ldots & \ldots & \ldots & \underline{302}\end{array}$

TABLE 7

Cosmetic Result

$\begin{array}{lllllllr}\underset{\text { Good }}{\text { Bad }} & \ldots & \ldots & \ldots & \ldots & \ldots & \ldots & 276 \\ \text { Indifferent } & . & \ldots & \ldots & \ldots & \ldots & \ldots & \text { I I } \\ & \text { Total } & \ldots & \ldots & \ldots & \ldots & \ldots & 302 \\ & \end{array}$

The tables indicate that the scheme of treatment described in this paper and carried out for some years at Black Notley Hospital has yielded results which are, on the whole, satisfactory. The cosit in time has been an average stay in hospital of I9 weeks, I6 weeks before operation and three afterwards. The general health of the patierus followed has been good; the cosmetic results ha been satisfactory, the term 'good' in this cothnection meaning one or more insignificant linear scars. There has been a local recurrence rate of under 4 per cent., as shown in Table 8 . What .尹f the incidence of extra-glandular lesions in late life ? Table 9 gives a tentative answer to thws question.

\section{TABLE 8}

ReCURRENCE OF GlandS

At Old Site

No Recurrence

Recurrence in Other Glands

Total ..

TABLE 9

SubSEQuENT Extra-Glandular Lesions

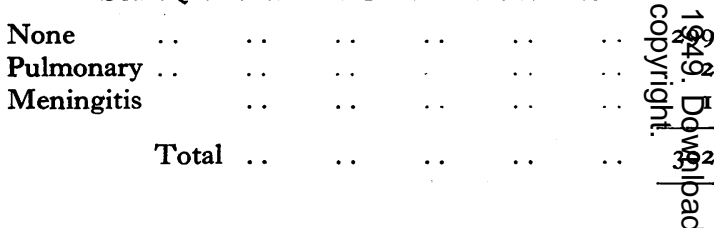

The information contained in this table is $\frac{\not}{\mathrm{B}}$ great interest and perhaps of profound significance. In only I per cent. of cases followed up for ôn average of three years has there been subsequemt extra-glandular tuberculosis and there is a notalofe - absence of skeletal and renal infection, the undoubted sequelae of bacillaemia. Does this in cate that a well-treated and healed primary tubèrculous lesion, far from being a hidden source $\overline{\text { of }}$ danger, is a shield against further infection? The assumption is tempting but many years must pass before it can be determined. 